$\mathbf{R}_{\text {ESEARCH }} \mathbf{P}_{\text {APER }} \longrightarrow$ FOOD SCIENCE

e ISSN-2230-9403 — Visit us : www.researchjournal.co.in Volume 9 | Issue 1 | April, 2018 | 156-162 DOI : 10.15740/HAS/FSRJ/9.1/156-162

\title{
Quality characteristics of blended wheat flour with Bajra, chickpea soybean and maize flours
}

\author{
Suvedita Katiyar and Rakhee Katiyar
}

An experiment was conducted on the quality characteristics of blended wheat flour of wheat variety RR-21 with four cereals/pulses viz., soybean, Bajra, maize and chickpea. Flour of each was prepared using the proportion by weight as 02 , 05,10 and $20 \%$ for evaluation of dough and chapati characteristics. The blending flours improved the water holding capacity of dough and recorded maximum in 20 per cent blending level. It was observed that blending of soybean and chickpea flour fairly improved the nutritional quality of flour upto $20 \%$ blending while maize and Bajra blending showed by and large no improvement in the quality of flour. All the blended wheat flour did not affect adversely and showed desirable dough quality at all four blended levels. Similarly the quality of chapaties and their taste were also desirable and fairly acceptable in all types of blended flour at all the levels.

Key Words : Blended wheat flour, Dough, Quality, Characteristics of chapati

How to cite this article : Katiyar, Suvedita and Katiyar, Rakhee (2018). Quality characteristics of blended wheat flour with Bajra, chickpea soybean and maize flours. Food Sci. Res. J., 9(1): 156-162, DOI : 10.15740/HAS/FSRJ/9.1/156-162.

Suvedita Katiyar, Department of Home Science, Juhari Devi

Intermediate College, Kanpur (U.P.) India

(Email : suveditakatiyar@gmail.com)

Associate Authors' :

Rakhee Katiyar, Government Girls High School, Aira Bhadiyar, Unnao (U.P.) India 